NBER WORKING PAPER SERIES

\title{
WELL-BEING, SOCIAL CAPITAL AND PUBLIC POLICY: WHAT'S NEW?
}

\author{
John F. Helliwell
}

Working Paper 11807

http://www.nber.org/papers/w11807

\author{
NATIONAL BUREAU OF ECONOMIC RESEARCH \\ 1050 Massachusetts Avenue \\ Cambridge, MA 02138 \\ December 2005
}

Condensed version of paper presented at the special session on well-being at the Annual Meetings of the Royal Economic Society, Nottingham, March 21, 2005. It was written while I was Killam Visiting Scholar, Institute for Advanced Policy Research, University of Calgary. I am especially grateful for the continued research collaboration of Haifang Huang, for hospitality and support from the University of Calgary and the Killam Foundation, for research support from the SSHRCC, and for data from the Statistics Canada RDC at UBC. In revising the paper, I am also grateful for helpful advice and suggestions from Curtis Eaton, Michael Jacobs, Daniel Kahneman, Richard Layard, Jason Riis and an anonymous referee. The views expressed herein are those of the author and do not necessarily reflect the views of the National Bureau of Economic Research.

(O)2005 by John F. Helliwell. All rights reserved. Short sections of text, not to exceed two paragraphs, may be quoted without explicit permission provided that full credit, including $\odot$ notice, is given to the source. 
Well-Being, Social Capital and Public Policy: What's New?

John F. Helliwell

NBER Working Paper No. 11807

December 2005

JEL No. I31, Z13, P52

\begin{abstract}
This paper summarizes recent empirical research on the determinants of subjective well-being. Results from national and international samples suggest that measures of social capital, including especially the corollary measures of specific and general trust, have substantial effects on well-being beyond those flowing through economic channels. Cross-national samples (supported by parallel analysis of suicide data) show large well-being effects from social capital and from the quality of government. Finally, Canadian life-satisfaction data show that several non-financial job characteristics, and especially the climate of workplace trust, have very large income-equivalent effects.
\end{abstract}

John F. Helliwell

Department of Economics University of British Columbia

997-1873 East Mall

Vancouver B.C. V6T 1Z1 CANADA

and NBER

john.helliwell@ubc.ca 


\section{Setting the Stage}

Although I and many other economists are newcomers to the study of well-being, the field has had many illustrious contributors over the centuries. Thus I have been lucky enough to act as research assistant for both Aristotle (in How's Life? Helliwell 2003) and Durkheim (Helliwell 2004). Working in Aristotle's lab, it has been natural to concentrate on measures of life satisfaction rather than questions dealing with happiness, since he thought that a reflective rather than a momentary view was more likely to give a balanced assessment of what constituted the good life, and to support his view that the good life steered a middle course between the Stoics and the Epicureans. To a striking degree, modern data have tended to support the main hypotheses of Aristotle and Durkheim, both of whom attached great importance to the norms and support networks that have more recently been described as social capital (Putnam 2000, OECD 2001).

In more recent work on well-being and the workplace, we are taking our methodology from Adam Smith by estimating the value of workplace social capital in terms of compensating or equalizing differentials (Helliwell and Huang 2005a). Smith (in the Wealth of Nations, book 1, chapter 10, part 1) and subsequent empirical researchers following his lead have tended to explain wage differences in terms of job characteristics. The key difficulty with explaining wages by job characteristics is that people of greater ability tend to find themselves jobs with both higher pay and better working conditions. This means that compensating differentials tend to be under-estimated, to the extent that differences in abilities cannot be properly controlled for. Measures of life satisfaction can be used to circumvent this problem, since the effects of income and non-income characteristics of the workplace can be included as separate determinants of life satisfaction, and the ratios of coefficients used to calculate compensating differentials. Adam Smith paid less attention to social capital than either Aristotle or Durkheim. The estimated compensating differentials for various measures of workplace trust and engagement are high enough to deserve his attention. 
Before turning to specific results, it might be helpful to complete the stage-setting by dealing in advance with some of the doubts that social scientists, and especially economists, might have about the use of subjective evaluations of life satisfaction as proxy measures of utility. This paper gives priority to a particular range of measures of well-being, especially those asking individuals to rate their life satisfaction on a scale of 1 to 10 . The answers to such questions are being used increasingly in applied studies designed to assess the effects of a variety of variables subject in various ways to public policy- e.g. the valuation of airport noise (van Praag and Baarsma 2005).

But are they the right questions? And can subjective answers to any such general questions be relied upon for either scientific or policy purposes? The use of such data in the ways I and others propose has been queried from several perspectives. First, there are those, among whom economists are often to be found, who are suspicious of subjective data of any kind, especially if there is any alternative possibility of inferring preferences from observed behaviour. The most effective answer to this type of scepticism is provided by the remarkable parallel between international results for life satisfaction and for suicide (Helliwell 2004), to be discussed later in the paper.

Second, among those who think that measures of subjective well-being are suitable objects of analysis, there are those who prefer to use samples or integrals of 'experienced utility' (Kahneman, Wakker and Sarin 1997) rather than reports of life satisfaction ('remembered utility') as the focus of attention. There is a wealth of experimental evidence (reviewed by Kahneman, Wakker and Sarin 1997, Kahneman et al 2004 and by Kahneman and Riis, 2005) that subjects generally evaluate the pleasure or pain of past experiences by some average based on the peak and final moments, and not on a sum or integral of their moment-by-moment reactions. This peak-plus-terminal rule appears to apply fairly broadly, whether the experience under review is a vacation or a colonoscopy. Studies show that it is this remembered utility rather than any more evenly weighted sum of momentary experienced utilities that tends to govern subsequent decisions, be they about where to take holidays or whether to have another colonoscopy. Kahneman argues that primary research and policy attention should be given to experienced utility, with the 
apparent dominance of remembered utility as a driver of individual decisions to be treated as a mistake. I am rather more inclined to conclude that if remembered utility produces a consistent set of forward-looking decisions and backward-looking evaluations, then it should be given pride of place by analysts and policy-makers. To focus on maximizing what the researcher takes to be the integral of individuals' experienced utility, if this is importantly at odds with what individuals remember, would seem bound to face voter rejection whenever exposed to the test of the ballot box. Since evaluations of remembered utility underlie currently reported life satisfaction, and have been shown to be the basis for individual-level decisions, they have credible claims as primary objects of policy-oriented research, providing a basis for both calculating and evaluating the effects of policy changes.

A third line of objection relates to the possibly confounding role of personality differences. Optimists will tend to say that they are satisfied with their lives. They may well have rosy valuations of their health status. They may also be more likely to be married, have interesting jobs, and spend time with their neighbours, all of which have been found to be positively correlated with life satisfaction. Only a few surveys have questions that provide adequate personality data to assess the likely extent of this sort of bias. But some indicative results to be reported later suggest that many of the key relationships apply almost equally to sub-samples drawn from different personality types, and hence are not solely or even predominantly attributable to personality differences.

There is also the related question of whether measures of life satisfaction have comparable meanings in different regional or national cultures. For example, King et al (2003) have found apparently differing uses of numerical scales in different societies, and advocate using anchoring vignettes as means of adjusting raw scores. To evaluate these risks, in the absence of specific anchors, Helliwell and Huang (2005b) use quintile averages, and population shares above particular numerical life satisfaction cut-off scores, as alternative dependent variables. Since these produce coefficient estimates strikingly like those based on national averages, international differences in scaling standards are not likely to lie behind the results reported here. 
It is also argued that there may be national differences in average personality or mood that make subjective data unreliable measures of physical health or life satisfaction. Kahneman and his collaborators suspect this to be the case. In support of this line of reasoning, they find (Kahneman and Riis, in press) a very high cross-national correlation for measures of life satisfaction and subjectively rated health, just as one would expect to find if there were international differences in expressed optimism or mood. To support this interpretation, they find no correlation between cross-country measures of subjective health and life expectancy in their sample comprising the richer European countries. Hence, they argue, there are grounds for treating international differences in both subjective health and life satisfaction as being 'reality free'. I am over-simplifying and probably overstating the case being made in Kahneman and Riis (in press) and Riis, Schwarz and Kahneman (2005), but the basic point should be clear, and it is important enough to need to be addressed.

One way of investing some reality in the cross-country differences in subjective measures would be to find them predictive of differences in behaviour. In this respect, it is useful to find that cross-country differences in subjective health add significantly (see Table 2) to the explained variance of suicide, with those populations reporting poorer average health having significantly higher suicide rates. Thus the subjective health data do appear to reflect reality, as shown by their ability to predict international differences in suicide behaviour.

The suicide data, which obviously reflect behaviour, and hence reality, can also be used to address Kahneman's fundamental concern that international differences in measured life satisfaction are in some sense too large to be believed. To illustrate the worry, Kahneman and Riis (in press) note that the World Values Survey measures of life satisfaction in the United States are higher than those in France by as much as the difference in life satisfaction between the employed and unemployed respondents in the United States. As shown in Helliwell (2004), the suicide data provide an independent way to judge whether the international variance of survey measures of life satisfaction is 
or is not too large to be believed. On the basis of a large Finnish survey (KoivumaaHonkanen et al 2001) that established baseline measures of life satisfaction followed up by twenty years of subsequent assessments of morbidity and mortality, it was possible to estimate, based on data from within a single country, a distribution of suicide conditional on the distribution of life satisfaction. This can then be applied to calculate hypothetical national suicide rates based on each country's distribution of answers to the life satisfaction question. This distribution predicts very well the mean and standard deviation of the actual international distribution of suicide rates. Since the international variability of measures of life satisfaction is therefore no greater than that implied by international differences in suicide rates, it seems reasonable to infer that both are equally well grounded in the same realities. At any rate, the international differences in life satisfaction do not, at least by this test, seem to be implausibly large.

This extended stage setting has been intended to show, by answering some plausible objections at the outset, that there is a good case to be made, beyond the recommendation of Aristotle (as quoted in Helliwell 2003, 332-3), for asking people to evaluate their lives, and for taking their answers seriously. Another more mundane reason for making use of rankings of life satisfaction is that there is a large body of such evidence already in hand, and the question is so simple to ask that it could in future be added at minimal cost to a wide variety of surveys commissioned for other purposes.

\section{Results: Interpersonal Differences}

\subsection{Demographics: Age, Gender, Marriage and Divorce}

Results in many countries are finding U-shaped patterns of well-being over the life cycle. Data from almost thirty years of Eurobarometer annual surveys in nine countries show that the shape of the distribution of age effects is largely unchanged from decade to decade, and hence cannot reflect differentially happy cohorts moving through the age distribution Research using a large recent cross-section of Canadian life satisfaction data suggests that perhaps one-third of the U-shape is removed if a separate variable is added based on the respondent's current estimate of stress related to work/life balance. 
The Eurobarometer data can also speak to gender and marital effects. For the European sample as a whole, including both genders in the same equation reveals a negative male effect of 0.05 in the early 1970s, gradually falling to zero in the 1990s. There are no corresponding trends in the marital status coefficients. For the roughly 500,000 observations of the whole European sample, relative to the unmarried base case, they are: living-as-married +.17 , married +.14 , separated -.30 , divorced -.17 , and widowed -0.10 all on the 4-point scale. Since some longitudinal studies have shown marriage effects rising to an early peak and then falling almost to baseline in the few subsequent years (Clark et al 2003), it has been suggested that marital status is subject to baseline or habituation effects, with only slight effects after habituation sets in. Under this interpretation, the large cross-sectional estimates might reflect personality differences, with genetically happy people being more likely to report high life satisfaction, and also to attract marriage partners. However, results based on the 2003 Canadian General Social Survey (GSS), show that there are no changes in the marital status coefficients when a personality-based variable is added for each individual.

\subsection{Income}

Relative income effects appear among respondents in both OECD and developing countries (Helliwell 2003), but are larger, and show no evidence of diminishing returns, in the developing world. Within OECD countries, in contrast, there appears to be little income-induced increase in life satisfaction once one's family income rises above the median income.

\subsection{The More We Get Together the Happier We'll Be}

Aristotle and the campfire song both foreshadow the results in Helliwell and Putnam (2004) showing the SWB effects of frequent contacts with family, friends and neighbours. Earlier empirical literature on social capital made use chiefly of data for various types of memberships (e.g. Putnam 2000), because these were all that were broadly available. Recent purpose-built surveys have probed deeper, and developed various measures of the intensity of social linkages. In results from the Canadian ESC survey, those respondents who have frequent contacts with family, friends and 
neighbours have SWB almost a full point higher, on the 10-point SWB scale, than others with no such contacts.

Trust is sometimes seen as consequence, as well as a facilitator, of frequently used networks. Life satisfaction appears to be related to various sorts of trust and also to the networks that may spawn or support trust. This mutual causality is thus likely to be difficult to disentangle, and there is also the issue of unmeasured personality differences, which are likely to influence trust, frequency of contacts, and life satisfaction, all in the same direction. Outgoing optimists may also, partly on the basis of their personalities, have better jobs and higher incomes. One way of testing the likely importance of personality-caused coefficient bias in the life satisfaction equations, is to test how robust are the estimates to the inclusion of a variable designed to capture a standard measure of personality. The 2003 Canadian General Social Survey (GSS) provide a good candidate measure, a 'mastery scale' based on answers to several questions designed to measure psychological coping resources (Pearlin and Schooler 1978, 20). It may run the risk of over-correcting for the effects of pure personality differences, since the answers document the extent to which respondents feel they are in command of their circumstances, so their answers are bound to be affected not just by underlying personality traits, but also by the circumstances they are currently facing. The results should be reassuring to those researchers who do not have personality variables to include in their analysis. As expected, the mastery variable is highly significant ( $>19$.). The coefficient on subjective health drops slightly (from 0.54 to 0.49 , but still maintaining a t-value $>40$.), something that should be expected, since it was otherwise the variable most likely to have been personality-driven.

The coefficients on social capital variables, such as time spent with family, friends and neighbours, and the trust placed in neighbours and the police, are unaffected by the inclusion of the personality variable. The negative SWB effects of further education, cet. par., are significantly greater when the mastery index is included, suggesting that education tends to increase respondents' confidence in dealing with their circumstances. 
2.4 Well-being and the Workplace

Recent research based on three different Canadian surveys (Helliwell and Huang 2005a) provides strikingly large and firmly established estimates of the value of several nonfinancial aspects of the workplace, and especially of workplace trust. For example, a onepoint change in job satisfaction, on a ten-point scale, would have the same well-being impact as a change of more than 0.5 in log income. These very large estimates of compensating differentials are rather precisely estimated, with t-values exceeding 6 in most specifications. Several measures of domain trust have strong linkages to subjective well-being, and workplace trust is the most important of all. To move up one-point on a ten-point scale of workplace trust is equivalent to a .17 change in log income (with a tvalue $=5$, see Helliwell and Huang 2005a, Table 5).

\section{Results: International Differences}

The World Values Survey has been evaluating life satisfaction and measures of social capital for more than twenty years in a growing number of countries. By combining individual observations from surveys taken in many countries, we have the possibility of combining individual and national-level data in the explanation of differences in wellbeing (e.g. Helliwell 2003). Analysis of the importance of national-level variables is limited by the relatively small number of countries and survey waves. Time is gradually solving this problem: there were 86 national observations from 49 countries in the first well-being paper, 117 observations from 50 countries in the suicide paper, and 136 observations from 57 countries for the latest equations shown in Table 1. These results are estimated entirely in terms of national averages, with variables found previously to be important at the individual level (divorce, belief in God and unemployment) being carried forward in combination with other variables with some combination of individual and contextual importance (membership densities and social trust) and the key national contextual variable, the quality of government as represented by indicators prepared at the World Bank by Kaufmann et al (2003).

\subsection{Life Satisfaction and Suicide Data Tell Consistent Stories}

Although using national-level data removes the chance for separating individual-level from national-level effects, it was done in the first instance to facilitate exactly 
comparable modelling of life satisfaction and suicide data. The suicide and well-being data, if they tell consistent stories, offer complementary advantages. The suicide results are not open to many of the objections made about the use of subjective data as dependent variables, while the well-being data, when and if their validity is established, can be easily and widely collected so as to permit low-cost evaluations. By contrast, suicides are such extreme and rare events that they are not suitable for routine community-level evaluations.

Table 1 shows the comparable results for the encompassing equation for suicide and well-being fitted for the 117-observation sample used in Helliwell (2004) and for a new larger sample, with almost identical results. In both samples the coefficients in the wellbeing and suicide equations are fully consistent in sign and closely comparable in standardized size (as shown by Figure 5 in Helliwell 2004). Coefficient differences appear where other studies suggest they might, with both religious beliefs and divorce having more impact on suicides than on SWB, and the reverse being the case for the quality of government. These differences, combined with international differences in these three variables, explain why Sweden can fit both equations almost exactly, while having top values for SWB and more average levels for suicides.

As already noted, Kahneman and colleagues have argued that international differences in SWB are suspiciously large and possibly reflective of differences in national mood rather than in objective well-being. The fact that the same equation fits national data for suicides and for well-being equally well and with comparable coefficients suggests that the SWB differences are substantive ${ }^{1}$. It is also worth assessing, to the extent possible, whether there are also some identifiable personality differences at the national level that might help to explain international differences in well-being and suicides. Eysenck and colleagues have done bilateral personality comparisons between Great Britain and many other countries, using the three-factor Eysenck personality questionnaire (Eysenck and

\footnotetext{
1 However, it is important to note that there is no significant correlation between suicide and SWB if the sample is restricted to the OECD countries, and the explanatory power of both equations is much reduced. Kahneman and colleagues have focused their attention on the OECD countries, while all of the equations reported in this paper make use of the much larger global samples, where the cross-sectional variance of almost all variables is much greater.
} 
Eysenck 1975). Steels and Ones (2002) have assembled these data into an internationally comparable data set, thus providing the means to test the effects of these personality variables for a subset of countries. We have done this for 73 observations covering 29 countries, with results shown in Table $1^{2}$. With only half the number of countries, the basic equations are somewhat weaker, but are consistent with the results from the larger sample. Of the three Eysenck factors, only the extraversion (e) index has significant effects, which it has in both equations. Those ranking high in extroversion are more likely to rank high in SWB and less likely to commit suicide. The psychoticism index enters the SWB equation significantly, but only when interacted with the measure of social trust. The coefficients imply that trust has a greater impact on SWB in those countries ranking higher on the psychoticism index.

Overall, adding the personality variables increases the explanatory power of both equations, especially that for suicide, without altering the pre-existing model structure. Thus it seems reasonable to conclude that international differences in measurable characteristics of personality do have some influence on both SWB and suicide rates. But this influence is above and beyond the explanatory power of the basic model, which appears to hold equally well whether or not account is taken of the available measures of international differences in personality.

Finally, Table 2 shows the effects of adding subjective health to both the suicide and SWB equations, supplemented by equations dividing the subjective health variable into three components: life expectancy at birth, a measure of morbidity (LE minus HALE, as noted previously), and a variable called HEARTY, whose observations are the residuals of an equation explaining subjective health by LE and MORBID. The importance of morbidity in the suicide equation should be no surprise, as mental illnesses contribute to the measure, and several types of mental illness (schizophrenia and bi-polar disorder in particular) pose high suicide risks. As already noted, subjective health has a significant impact on the suicide rate, with the other equations showing that this effect is especially

\footnotetext{
${ }^{2}$ The $t$-values are based on robust standard errors calculated on the (correct) assumption that errors are clustered by country.
} 
strong from the morbidity variable and the psychological and related conditions covered by HEARTY. In the well-being equation, life expectancy and the residual variable are the most important components, with morbidity being less important.

\subsection{How Much Does Good Government Matter?}

The quality of government, as measured by different averages of the six main Kaufman et al (2003) measures, has a strikingly large influence in explaining international differences in SWB. It is worth noting that these assessments are not done by the respondents to the surveys, and are hence not subject to the risk of excluded personality factors that might bias the results. In any event, as already seen in Table 1, including explicit measures of international personality differences does not lessen the estimated effects of governmental quality. The six measures can be divided into two groups that have different effects, at least in some samples. One group of four variables (called GOVDO) relates to the honesty and efficiency of government, with the four dimensions relating to effectiveness, regulatory efficiency, rule of law and lack of corruption. The second group (GOVDEM) relates more to the operation of the democratic process, capturing aspects of voice and accountability, and of political stability. Tests reported in Helliwell and Huang (2005b) show that GOVDO matters more to the poorer countries, while GOVDEM matters more among the richer countries.

\section{Policy Implications}

\subsection{The Importance of Engagement}

People apparently care a lot about the social context within which they work and play. Whatever their personality type, they value trust in their neighbourhoods, their workplaces, their public services and their public servants. Trustworthy environments both support and are supported by frequency of (successful) contacts. If these results should prove as robust as they thus far seem to be, they would seem to have important implications for all types of policies and behaviour.

People directly value their engagement with others, including their involvement in the process making public decisions and delivering public services. This suggests providing 
room for local initiative in the design and delivery of public services. For example, Frey and Stutzer (2000) found subjective well-being higher in Swiss cantons with more frequent consultations with their electors, and Chandler and Lalonde (1998) found that several measures of community-level self-government were associated with dramatically lower suicide rates among Aboriginal communities in British Columbia. There is also evidence that policies deliberately designed to foster engagement, for example the controlled welfare-to-work experiments in New Brunswick and British Columbia, produced changes in beliefs such as to support continuing engagement (Gottschalk 2005).

The sizes of the estimated compensating differentials for non-financial features of the workplace suggest that both private and public employers need to think again about the way they treat their employees and each other. As Richard Layard (2005) argues, the trend towards short-term commitments, and the increasing of linking monetary and other rewards to individual performance targets, especially short-term ones, may be having corrosive effects on trust and loyalties and creating unhappiness in the process. Once the importance of trust and engagement are digested, they might be expected to inform almost every policy decision about the form and delivery of public services. We might expect to see more provision of multi-use public spaces; more linkage among generations in the provision of care, education, and leisure; provision of better ways for community newcomers to give as well as get public services and social contacts; meshing of voluntary and professional workers in more effective ways; and changing the nature of the lessons and myths that inspire education. In particular, it is incumbent on economists especially, who have been responsible for propagating the myth of economic man, to at least consider the costs of policies that rely too much on its assumed truth.

\subsection{Data and Research}

Although much can be learned simply by taking on board the wealth of existing studies in many disciplines, well-being research will become part of policy-makers' regular assessments only if and as the data and research accumulate in quality and quantity. A fairly small set of questions can provide useful assessments of the level and distribution of well-being, and of the types of social capital and institutions that support it. As these 
data come to be more widely available, and as time series accumulate, it should be possible to learn more about what types of institutions and initiatives are likely to be successful, and in what circumstances. Although I have argued that remembered utility, of the type embodied in answers to life satisfaction questions, has not just an Aristotelian cachet but also explanatory power, I would agree with those who see the benefits of a much broader and richer set of assessments. The supporting psychological, neurological and experiential assessments that are already in progress could and should be used to enrich, change, and supplement the more easily and broadly available measures of wellbeing. The world is complex, and best understood with many measures, and seen through many lenses. Simple and widely collected measures of social capital and well-being have earned a place in the researcher's toolkit.

\section{References}

Clark, A., E. Diener, Y. Georgellis, and R.E. Lucas (2003) 'Lags and leads in life satisfaction: A test of the baseline hypothesis', CNRS working paper. Paris: DELTA.

Chandler, M.J. and C. Lalonde (1998) 'Cultural continuity as a hedge against suicide in Canada's First Nations', Journal of Transcultural Psychiatry 35: pp. 191-235.

Eysenck, H.J. and S.B.G. Eysenck (1975) Manual of the Eysenck Personality Questionnaire London: Hodder \& Stoughton.

Frey, B.S. and A. Stutzer (2000) 'Happiness, economy and institutions' Economic Journal vol 110 (446), pp. 913-38.

Gottschalk, Peter (2005) 'Can work alter welfare recipients' beliefs?' Ottawa: SRDC Working Paper . www.srdc.org/english/publications/gottschalk.pdf

Helliwell, John F. (2003) 'How's life? Combining individual and national variables to explain subjective well-being', Economic Modelling, vol 20, pp. 331-60.

Helliwell, John F. (2004) 'Well-being and social capital: does suicide pose a puzzle?' NBER Working Paper 10896.

Helliwell, John F. and R.D. Putnam (2004) 'The social context of well-being' Phil Trans R. Soc Lon. B vol. 359, pp. 1435-46. Reprinted in F.A. Huppert, B. Kaverne and N. Baylis, eds., The Science of Well-Being. London: Oxford University Press, 2005.

Helliwell, John F. and H. Huang (2005a) 'How's the job? Well-being and social capital in the workplace'. NBER Working Paper 11759. 
Helliwell, John F. and H. Huang (2005b) 'How's your government? International evidence linking good government and well-being', Paper for Oxford conference in honour of John Flemming, September 2005, and the Göteborg conference on the quality of government, November 2005.

Kahneman, D., A.B. Kreuger, D.A. Schkade, N. Schwarz, and A.A. Stone (2004) 'A survey method for characterizing daily life experience: the day reconstruction method'. Science vol. 306: pp. 1776-80.

Kahneman, D. and J. Riis (2005) 'Living, and thinking about it: two perspectives on life'. In F.A. Huppert, B. Kaverne and N. Baylis, eds., The Science of Well-Being. London: Oxford University Press.

Kahneman, D., P.P. Wakker, and R.Sarin (1997) 'Back to Bentham? Explorations of experienced utility'. Quarterly Journal of Economics vol. 112(2), pp. 375-405.

Kaufmann, D., A. Kraay and M. Mastruzzi (2003) 'Governance matters III: updated indicators for 1996-2002.' (Washington: World Bank)

King, Gary, Christopher J.R. Murray, Joshua A. Salomon, and Ajay Tandon (2003) "Enhancing the Validity and Cross-Cultural Comparability of Measurement in Survey Research." American Political Science Review vol 97(4), pp. 567-83.

Koivvumaa-Honkanen, H., R. Hokanen, H.H. Viinamäki, K. Heikkilä, J. Kaprio and M. Koskenvuo (2001) 'Life Satisfaction and Suicide: A 20-Year Follow-Up Study'. American Journal of Psychiatry vol. 158, pp. 433-9.

Layard, Richard (2005) Happiness. London: Penguin.

Organization for Economic Cooperation and Development (2001) The Well-Being of Nations: The Role of Human and Social Capital. Paris: OECD Centre for Educational Research and Innovation.

Pearlin, L.I. and C. Schooler (1978) 'The structure of coping'. Journal of Health and Social Behavior vol. 19(1), pp. 2-21.

Putnam, R. (2000) Bowling Alone: The Collapse and Revival of American Community. New York: Simon and Schuster.

Riis, J., N. Schwarz and D. Kahneman (2005) 'Some international differences in health are reality free: implications for happiness. (manuscript in preparation).

Steel, P. and Ones, D. (2002) 'Personality and happiness: a national level analysis', Journal of Personality and Social Psychology vol. 83(3), pp. 767-81. 
Van Praag, B.M.S. and B.E. Baarsma (2005) 'Using happiness surveys to value intangibles: the case of aircraft noise'. Economic Journal, vol. 115 (January), pp. 224-46.

Table 1: Comparing well-being and suicide equations, with different samples, and adding personality factors

\begin{tabular}{|c|c|c|c|c|c|c|c|c|}
\hline \multirow{3}{*}{ Sample } & \multicolumn{3}{|c|}{$\begin{array}{l}\text { Comparing current sample with } \\
\text { previous sample }\end{array}$} & \multicolumn{5}{|c|}{$\begin{array}{l}\text { Testing cross-country personality factors } \\
\text { in a smaller sample }\end{array}$} \\
\hline & 117-obs Sample & \multicolumn{2}{|c|}{ 136-obs Sample } & \multicolumn{2}{|c|}{ 72-obs Sample } & \multirow[b]{2}{*}{ Isatis } & \multirow[b]{2}{*}{ Isatis } & \multirow[b]{2}{*}{ Isatis } \\
\hline & suicide Isatis & suicide & Lsatis & suicide & suicide & & & \\
\hline Average memberships & -6.08 & -5.342 & 0.346 & -3.925 & -3.702 & 0.206 & 0.049 & 0.014 \\
\hline & {$[2.45]$} & [3.00] & [2.52] & {$[2.72]$} & {$[2.48]$} & {$[1.90]$} & {$[0.51]$} & {$[0.16]$} \\
\hline \multirow[t]{2}{*}{ Social trust } & -16.47 & -16.196 & 1.895 & -9.355 & -13.309 & 2.569 & 1.646 & 1.673 \\
\hline & {$[2.42]$} & [2.49] & [3.66] & {$[0.96]$} & [1.47] & [3.55] & [2.52] & [2.92] \\
\hline \multirow[t]{2}{*}{ Belief in God } & -22.82 & -21.419 & 1.746 & -21.901 & -7.275 & 2.152 & 2.445 & 1.839 \\
\hline & {$[5.35]$} & [5.92] & {$[5.61]$} & {$[4.89]$} & {$[1.67]$} & {$[4.25]$} & {$[5.12]$} & [3.03] \\
\hline \multirow[t]{2}{*}{ Divorce } & -0.19 & 4.41 & -0.176 & 5.714 & 5.789 & -0.25 & -0.237 & -0.238 \\
\hline & [5.37] & [5.97] & [3.64] & [7.12] & [9.19] & [4.89] & {$[4.97]$} & {$[5.44]$} \\
\hline \multirow[t]{2}{*}{ Unemployment rate } & 0.11 & 0.056 & -0.03 & 0.082 & 0.035 & -0.031 & -0.029 & -0.027 \\
\hline & [0.58] & [0.34] & [2.47] & {$[0.36]$} & {$[0.15]$} & {$[2.26]$} & {$[2.11]$} & [2.03] \\
\hline \multirow[t]{2}{*}{ Govdo } & -1.66 & -1.458 & 0.78 & -4.128 & -2.578 & 0.713 & 0.742 & 0.678 \\
\hline & [10.31] & [1.83] & [10.02] & {$[4.05]$} & [2.62] & [7.70] & [8.95] & [6.53] \\
\hline \multirow[t]{2}{*}{ Extroversion } & & & & & -2.673 & & & 0.119 \\
\hline & & & & & [3.98] & & & [1.90] \\
\hline Trust ${ }^{\star}$ Psychoticism & & & & & & & 0.292 & 0.339 \\
\hline & & & & & & & [3.60] & [3.36] \\
\hline \multirow[t]{2}{*}{ Constant } & 23.73 & 23.19 & 5.364 & 19.043 & 62.702 & 5.277 & 5.057 & 3.072 \\
\hline & [22.28] & [5.65] & [20.32] & {$[3.48]$} & {$[5.04]$} & [15.57] & {$[15.84]$} & [3.07] \\
\hline Observations & 117 & 136 & 136 & 72 & 72 & 72 & 72 & 72 \\
\hline R-squared & 0.81 & 0.61 & 0.78 & 0.61 & 0.7 & 0.81 & 0.83 & 0.85 \\
\hline
\end{tabular}


Table 2: Adding Life expectancy, morbidity years and hearty*

\begin{tabular}{|c|c|c|c|c|c|c|c|c|c|c|}
\hline \multirow{2}{*}{$\begin{array}{r}\text { Sample } \\
\text { D.V. }\end{array}$} & \multicolumn{5}{|c|}{ 136-obs Sample } & \multirow[b]{2}{*}{ Isatis } & \multirow[b]{2}{*}{ Isatis } & \multirow[b]{2}{*}{ Isatis } & \multirow[b]{2}{*}{ Isatis } & \multirow[b]{2}{*}{ Isatis } \\
\hline & Suicide & Suicide & suicide & suicide & suicide & & & & & \\
\hline \multirow[t]{2}{*}{ Average memberships } & -2.069 & -5.094 & -2.684 & -2.63 & -4.767 & 0.047 & 0.33 & 0.107 & 0.107 & 0.325 \\
\hline & {$[1.13]$} & [3.25] & {$[1.48]$} & {$[1.49]$} & {$[3.14]$} & {$[0.35]$} & [2.36] & {$[0.76]$} & {$[0.76]$} & [2.35] \\
\hline \multirow[t]{2}{*}{ Social trust } & -7.448 & -13.453 & -4.437 & -3.161 & -11.317 & 0.299 & 1.72 & 0.363 & 0.361 & 1.689 \\
\hline & {$[1.02]$} & [2.16] & {$[0.66]$} & {$[0.46]$} & {$[1.77]$} & {$[0.54]$} & [3.23] & {$[0.79]$} & {$[0.78]$} & [3.26] \\
\hline \multirow[t]{2}{*}{ Belief in God } & -17.493 & -24.191 & -19.957 & -21.36 & -25.215 & 1.146 & 1.923 & 1.25 & 1.252 & 1.938 \\
\hline & [5.45] & {$[7.06]$} & [6.03] & {$[6.05]$} & [7.13] & [3.29] & [6.41] & {$[3.55]$} & {$[3.64]$} & [6.55] \\
\hline \multirow[t]{2}{*}{ Divorce } & 3.728 & 3.523 & 3.168 & 3.16 & 3.508 & -0.11 & -0.12 & -0.082 & -0.082 & -0.119 \\
\hline & {$[5.31]$} & [5.38] & [4.98] & {$[4.77]$} & [4.97] & [2.08] & [2.16] & {$[1.58]$} & {$[1.58]$} & [2.15] \\
\hline \multirow[t]{2}{*}{ Unemployment rate } & 0.062 & 0.05 & 0.107 & 0.113 & 0.063 & 0.044 & -0.03 & -0.036 & -0.036 & -0.03 \\
\hline & {$[0.31]$} & {$[0.33]$} & [0.67] & {$[0.71]$} & {$[0.43]$} & [3.42] & {$[2.56]$} & {$[3.46]$} & [3.47] & [2.61] \\
\hline \multirow[t]{2}{*}{ Govdo } & 0.82 & 1.925 & 3.226 & 2.297 & 0.872 & 0.58 & 0.565 & 0.461 & 0.462 & 0.581 \\
\hline & {$[0.86]$} & {$[1.58]$} & [2.41] & {$[1.72]$} & {$[0.70]$} & {$[5.48]$} & {$[4.36]$} & {$[4.24]$} & [4.12] & {$[4.08]$} \\
\hline Self-reported health & $\begin{array}{r}-10.028 \\
{[2.86]}\end{array}$ & & & & & $\begin{array}{l}1.208 \\
{[5.39]}\end{array}$ & & & & \\
\hline Healthy Life Expectancy & & $\begin{array}{r}-0.832 \\
{[3.23]}\end{array}$ & $\begin{array}{r}-1.058 \\
{[4.10]}\end{array}$ & & & & $\begin{array}{l}0.053 \\
{[2.04]}\end{array}$ & $\begin{array}{r}0.07 \\
{[3.62]}\end{array}$ & & \\
\hline Total Life Expectancy & & & & $\begin{array}{r}-0.653 \\
{[2.04]}\end{array}$ & $\begin{array}{r}-0.378 \\
{[1.15]}\end{array}$ & & & & $\begin{array}{l}0.069 \\
{[2.90]}\end{array}$ & $\begin{array}{l}0.046 \\
{[1.36]}\end{array}$ \\
\hline \multirow[t]{2}{*}{ Morbidity Years } & & & & 1.998 & 1.864 & & & & -0.071 & -0.068 \\
\hline & & & & {$[3.08]$} & [3.01] & & & & {$[2.16]$} & [2.07] \\
\hline \multirow[t]{2}{*}{ Hearty* } & & & -8.587 & -7.877 & & & & 1.07 & 1.069 & \\
\hline & & & {$[2.54]$} & [2.35] & & & & {$[4.75]$} & [4.89] & \\
\hline \multirow[t]{2}{*}{ Constant } & 54.123 & 76.688 & 84.893 & 46.743 & 33.481 & 1.875 & 1.959 & 1.735 & 1.786 & 2.594 \\
\hline & {$[4.74]$} & {$[4.59]$} & {$[5.11]$} & {$[1.76]$} & {$[1.24]$} & [2.51] & [1.21] & {$[1.41]$} & [0.99] & [1.06] \\
\hline Observations & 103 & 136 & 131 & 131 & 136 & 103 & 136 & 131 & 131 & 136 \\
\hline R-squared & 0.64 & 0.65 & 0.68 & 0.69 & 0.67 & 0.81 & 0.79 & 0.83 & 0.83 & 0.79 \\
\hline
\end{tabular}

* Hearty is the part of self-reported health status uncorrelated with life expectancy and morbidity. For wave 4 of the WVS, when the health question was omitted, hearty takes its average value for previous waves. 